DOI: https://doi.org/10.47405/mjssh.v6i10.1077

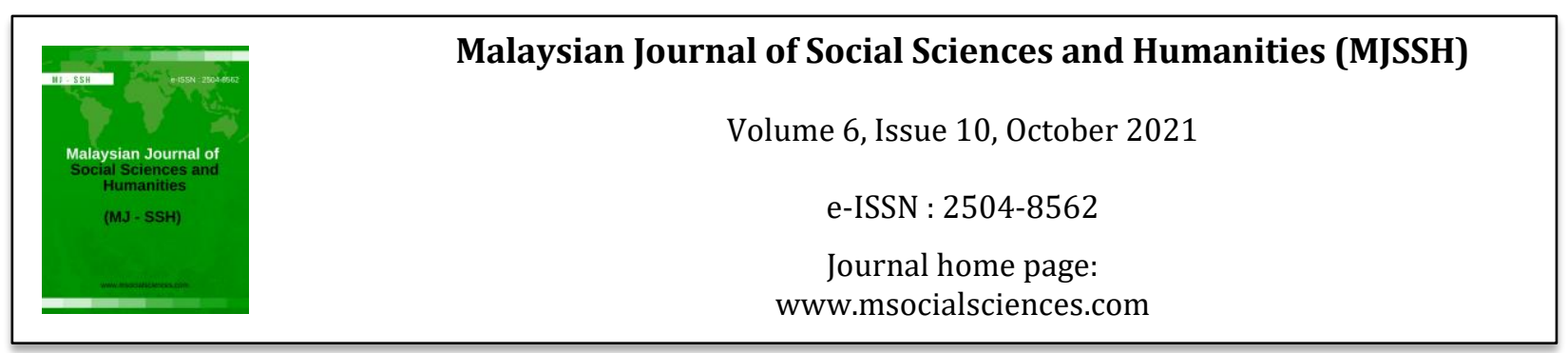

\title{
Criminalising Mental Disorder-Induced Attempted Suicide in Malaysia: Breaking the Silence
}

\author{
Adneen Sofia Binti Muhammad Adamin Ghazalee1, Kamar Azureen Binti Kamaruzaman', Nur \\ Jannah Binti Khairul Anuar1, Nur Syazana Binti Md Salleh1, Nurus Sakinatul Fikriah Binti Mohd \\ Shith Putera1, Hartini Binti Saripan'1 \\ ${ }^{1}$ Faculty of Law, Universiti Teknologi MARA, 40450 Shah Alam, Malaysia
}

Correspondence: Nurus Sakinatul Fikriah Binti Mohd Shith Putera (nurussakinatul@uitm.edu.my)

\begin{abstract}
Every 40 years, a person commits suicide somewhere in the world. Suicide claims the lives of over 800,000 individuals each year, accounting for about 1.4 percent of all deaths globally. In this spectrum, mental disorders are among the strongest predictors of suicide attempts with depression, substance abuse, and psychosis being the most common risk factors. Regardless of suicides being an unprecedented epidemic in the society, Malaysia is one of the few which remains the archaic law in statutes, that criminalises suicide and punishes anyone who attempts or commits any act leading to the commission of such an offence with a sentence of one year in prison, a fine, or both. The present research thus aims at highlighting the challenges of prosecuting attempted suicides in Malaysia based on the attitude of the judiciary, thus addressing the weaknesses of Section 309 of the Penal Code of which the provision for criminalising suicide rests. Employing the doctrinal research methodology, systematic means of legal reasoning based on statutory materials, conventional legal theories, and related case law pertinent to the criminalising of attempted suicide in Malaysia are produced. In dealing with issues as intricate as suicides and mental disorder, the present research argues that the focus should be to develop a regulatory framework that facilitate access to appropriate care in a professional and sensitive manner instead of punishment.
\end{abstract}

Keywords: attempted suicide, decriminalising attempted suicide, mental disorder

\section{Introduction}

Within the world view, suicidal behaviour is one of the paramount causes of injury and death. Information about the epidemiology of such behaviour is important for policymaking. This is especially true for a provision that had remained untouched since it came into force, thus warranting a relook and repeal as per today's scientific understanding of the subject and societal attitude had changed and developed through time and vast civilization. (Prakash, Behere, Mulmule, 2020). Suicide is one of the most calamitous outcomes in clinical institution and practice (Douglas, Baldessarini, Yeates, 2010). It is not predictable in the individual and results from a complex and vast series of contributing factors that may differ across individuals, yet 30\%-70\% of suicides occur in patients who are receiving some treatment and also possible for those who are not (Fawcett, 2012). Despite an increase in the treatment of suicidal persons over the past decade, incidence rates of suicidal behavior have remained largely unchanged and the statistics are worrying on the fact that many initiatives have been implemented (Harris, Baraclough, 1997). 
There is no reality in Malaysia where suicide is an irrelevant or petty social issue (Nge, Farah, 2012). It is especially alarming now, in 2020, where the world has been shaken by the global pandemic, COVID-19 that has undoubtedly crumbled national economies and taken a toll on the mental livelihood of most. This pandemic has increased the risks of individuals attempting suicide. For example, a pilot had committed suicide by jumping off a condominium unit in Serdang after he was retrenched by his airline company in August 2020, where many companies had to let go of their workers as they either went bankrupt or were struggling to stay afloat (The Star, 2020). Furthermore, based on various media reports, Malaysian firemen have been immensely occupied as they have received increasing demands in handling attempted suicide cases since the locally enforced Movement Control Order (MCO) in March 2020 Nortajuddin, 2020). This statement is strengthened by the nation's National Fire and Rescue Department Operations Director, Nor Hisham Mohammad who told reporters between March and July this year, the department had attended to more than 80 cases, with 78 people rescued, seven injured and three fatalities and added their busiest month was June with 21 cases of attempted suicide across the country. In addition, globally, suicide is still a worrying social problem and according to a report by the World Health Organization in 2016, low to middle income groups had a higher rate- with a huge gap- of suicide compared to those from high income groups (World Health Organization, 2016). Clearly, these facts prove how low-income groups are prone to suicide and there is a pressing need for Malaysian law to enact a feasible legislation in governing suicide attempts.

According to the definition under the Cambridge Dictionary, the act of suicide is the act of oneself ending their own life intentionally. Attempted suicide or non-fatal suicidal behaviour is self-injury with at least some desire to end one's life that does not result in death. Assisted suicide is when one individual assist another or provide an aid which bring about the desired death of the individual who wished to bring his life to ends. It may be done indirectly via providing either advice or the means to the end. This is in contrast to euthanasia, where usually another person usually a medical practitioner takes a more active role in bringing about a person's death. As defined by Cambridge Dictionary, suicidal ideation is the thoughts of ending one's life but not taking any active efforts to do so where it may or may not involve exact planning or intent and the thought itself does not necessarily provide a practical alternative. Thus, suicide can be seen as something that is not foreign among the society as it is something that had happened with a striking trend lately. With a very much easy verb of 'suicide' to understand, the act of suicide exist with an unclear interpretation as the background of the people with suicidal behaviours might have a link with psychosocial disability without being medically recognised as one with a clear diagnosis. Hence, an insight to the assessments per the individual with suicidal behaviour must be look into in order to gain deeper understanding about the subject matter of this research, the suicide offenders. Suicide in the context of criminal role reflects a significantly complex interaction, thus requiring authorities to appreciate the theories of punishment to better address the issue.

\section{Literature Review}

Globally, it is estimated that 1 million lives are stripped by suicide annually with a devastating $60 \%$ of that calculation takes place in Asia (Chen, Chien-Chang Wu, Yousuf \& Yip, 2011). If commonly used estimates are applied to Asia, very nearly 10 to 20 times as many suicide attempts occur not resulting to deaths and five to six people affected by each suicide death, suicide may impact more than 60 million people may be yearly. As many as $93 \%$ of suicide attempters were found to demonstrate mental health disorder at the time of the commission of the act, though only 33-50\% of the suicide survivors had contact with psychiatrists (Roh, 2011). In this setting, the Malaysian Medics International (MMI) also stressed the immediate need to tackle mental health disorders, citing the National Health and Morbidity Survey 2019 that identified close to 500,000 adults in Malaysia are known to suffer from depression (Blue, 2020). Certainly, this data should not be ignored as people who are highly prone to attempting suicide often have depression and psychoses (Sinniah, Maniam, Oei \& Subramaniam, 2014). Peculiarly, in Malaysia, the act of attempted suicide is governed by Section 309 of the Penal Code, providing that whoever attempts to commit suicide and does any act towards the commission of such offence, shall be punished with imprisonment for a term which may extend to one year or with 
fine or both. This provision suggests that an individual's mental state is immaterial to prosecution, thus demands that one be criminalized if they attempt suicide.

Under this provision, if an individual is caught attempting suicide at the preparatory stage like after writing a suicide note, while tying a noose around his neck to hang him or already hanging himself but the rope snaps and he lives, it is not a crime. The criminalization of attempted is believed to have its root in the role of criminal law to impede immoral behaviour within the society as well as strong religious and cultural sentiments prohibiting suicide (Ball, 1956). Even though many jurisdictions hold the same legal position as Malaysia, the global perception has witnessed a change in suicide laws where jurisdictions like the United Kingdom, North America, the European Union and most of Asian countries have implemented regulations or amended their suicide laws in developing a more comprehensive approach towards mental health and suicide (Moore, 2000). In this context, suicide is an act of self-harm usually provoked by a mental disease, therefore the law governing suicide should be different in nature with the law governing other crimes (Shah, 2018). At this juncture, the biggest question is whether these individuals are criminals by nature to begin with, which they are not as persons with a mental health disorder does not have a conscious intention of violating the law but are clouded by chemicals controlling their brain which can lead to suicide. With this being said, a penal deterrent will better accommodate criminal acts instead of acts done by individuals clinically certified to be in mental anguish (Chia, Yee, Choo, 2010). Past literatures are replete with the interwoven conflict between the rationale behind the criminalization of attempted suicide and the call for a more pragmatic care-based framework for individuals with suicidal ideation.

This wind of change for instance, is most apparent in India with its decade of journey towards the decriminalization of suicide by repealing its Section 309 of the Penal Code, given the astronomic rise of suicide cases (Vijayakumar, 2010). As of 2019, India reports an average of 274 daily suicide cases, where a failure of the attempt was 20 times higher than completed suicide (Pal, 2017). This is detrimental to the nation's development as most people below the age of 44 years old, which are youth and future leaders were prone to commit suicide (Goswami, 2018). This research has chosen India as a country of reference for the decriminalization of suicide because of the similarity of social and cultural background of its citizens. For example, the majority of the Indian of community believe in Hinduism which considers suicide a sin (Vijayakumar, 2008). Similarly, a majority of Malaysians believe in Islam, with most of the remaining believing in Christianity or Hinduism (Ibrahim, 2019). Thus, these beliefs reflect the perception formed around catering to mental health disorder and attempted suicide whereby victims are treated as criminals and a disgrace. Despite dialogues and debates on the call to decriminalize suicide in Malaysia, insignificant weight of discussion has been provided on the adequacy and effectiveness of the laws governing attempted suicide, (Harun, 2020) particularly the challenges in prosecuting and the judicial attitude surrounding attempted suicide in Malaysia. These premises have compelled this research to revisit the relevant laws governing attempted suicide in Malaysia by benchmarking the Indian legal position. Based on the current background of the legal framework on the offence of attempted suicide, the problem statement is scrutinized in the next section.

\section{Methodology}

In the context of this research, the doctrinal research is conducted to synthesize numerous statutory provisions, regulatory principles, case law (Hutchinson \& Duncan, 2014) related to criminalising attempted suicide and mental health issues. The primary aim of this method is also explored in interpreting normative critics for the formulation of proposals for the future endeavours. In so much as this research is concerned, the sources for the doctrinal analysis approach are obtained in the form of written sources such as statutory legislation, case law, regulation guideline documents, and reports retrieved from a library-based search. The library-based search was aided by the UiTM Online Public Access Catalog (OPAC) system to identify primary data such as the Malaysian Penal Code, the Indian Penal Code and the Mental Health Act 2001. Whereas the secondary data consisted of journal articles and reports were obtained by browsing law databases such as the Malayan Law Journal, the Current Law Journal, HeinOnline and other databases namely Springer, ScienceDirect, SAGE, Emerald and others. 


\section{Result}

The research identifies that the existing legal framework is inadequate in governing attempted suicide associated with mental health disorders in Malaysia. This leads to incompatibility and the inefficiency of Section 309 of the Malaysian Penal Code in addressing the issue of attempted suicide rooted in mental difficulties.

According to the World Health Organisation (WHO), it estimates that each year approximately one million people died from suicide, which represents a global mortality rate of 16 people per 100,000 or one death every 40 seconds. It is predicted that by 2020 the rate of death will increase to one every 20 seconds. At this background, law plays a pivotal role in protecting the sanctity of life and cannot be seen to condone the taking of human life although it is self-inflicted.

This must be preserved all whilst maneuvering the underlying causes of suicide that are mostly rooted with mental difficulties. Attempted suicide is governed under Section 309 of the Malaysian Penal Code where the person charged for attempted suicide if prosecuted, would be imprisoned or be imposed a fine. The provision does not expressly provide a suitable avenue for people with mental health disorders or suicidal ideation ( $\mathrm{Ng} \&$ Panirselvam, 2019). Instead of litigation and punishment, the focus should be directed to facilitate access to appropriate care in a professional manner instead of acting as an impractical law camouflaged as a legal deterrent for society. According to former Health Minister Datuk Seri Liow Tiong Lai in 2012, he argued that antisuicide laws in Malaysia are no longer relevant, as the law is not providing treatment to the charged person but punishing them instead (Wen, 2021).

Adinkrah in 2016 wrote that suicidal persons require mental health treatment modalities such as psychological counselling, psychotherapy, economic and material assistance instead of financial penalties or punitive incarceration (Adinkrah, 2016). Conforming to the theories of punishment, the aim of criminal law is apart from punishing is stretched to deter, rehabilitate, and offer a form of retribution to society. In light of the current circumstances, the law on prosecuting attempted suicide as a deterrent does not yield any benefit to the charged person nor the society as anti-suicide laws inflict additional torture and degradation by punishment, which is unreasonable and unwarranted. The objective of deterring future attempted suicide is not achieved by criminalizing suicidal behaviour. Instead, it could worsen the condition of the suicidal person, especially if their mental condition is left untreated.

Consequently, it can be said that the punishment serves no purpose, indeed, it may prove to be selfdefeating and counterproductive. This can be supported by Adinkrah's report in 2016 where he affirms that the imposition of financial penalties on attempted suicide offenders had not been a sufficient deterrent penalty. In this setting, David Jaros, a law professor from the University of Baltimore, commented that saddling a person who has mental health disorder with jail time is a "poor use of discretion'. As stated by Jaros, "This (prosecuting attempted suicide) is a classic example of how the criminal justice system can ultimately create hurdles for a person trying to get the help they need" (Fenton, 2018).

Unlike the Mental Healthcare Act that was enacted in India in 2017 which provides a "patient-centric" measure for persons with mental illness, Section 309 of the Malaysian Penal Code prevents reporting of suicide and does not furnish any kind of mental health support (The Indian Express, 2017). Based on a paper written by Joseph Osafo in 2017, anti-suicide laws are insensitive to the mental health needs of suicidal persons because it is punitive. The law does not provide for the chance of mental assessment, instead it is used as apart from police investigation for the establishment of criminal evidence in court (Osafo, Akotia, N.B Quarshie, Boakye \& Andoh-Arthur, 2017). Not just that, there seems to have a lack of actual prosecutions against those who attempt suicide as it appears to be rare. Police officers tend to not prosecute cases of attempted suicide but mark it as 'No Further Action'(NFA) instead. This was brought up by State Police Central Intelligence and Crime Unit officer DSP Yazrie Ismail where he claimed that the police would not recommend the cases to be tried in court and they suggested the NFA to prevent more stress to the accused. This is because, a person who attempted suicide has already 
shown signs that their mental health is not stable, and the enforcement authorities do not want to intensify the persons' mental and psychological condition because clearly, they need professional help (Daily Express Online, 2021).

Therefore, Section 309 of the Malaysian Penal Code is rarely enforceable, and due to the fact that the police refuse to utilize the provision, cases of attempted suicide may be left substantially underreported. By reason of the problems in prosecuting and enforcement, the number of reported cases of suicide attempts are likely to be highly unreliable. The rate of attempted suicide is usually left undocumented because enforcement authorities do not report non-fatal acts of suicide. This can also be explained in light of the nature of the anti-suicide laws in Malaysia being associated with criminal offences. Individuals and families of the suicidal person may refuse to seek the necessary mental and medical treatments in fear of prosecution (Mike, 2020). Lam Thye, a member of the Mental Health Advisory Council, reported that when suicide is considered a criminal act, suicide attempts are hidden and suicide deaths will go unreported, thus giving a false perception that suicidal behaviors are less prevalent (Mae, 2021). Therefore, because of the criminal nature of the suicide laws in Malaysia, suicidal individuals are afraid to come forward to seek help which results in the under-reporting of attempted suicide and inaccurate data on suicide attempts.

\section{Discussion}

On a global scale, annually an estimated 1 million lives are sacrificed induced by suicide with a devastating $60 \%$ of that calculation occurring in Asia (Chen, Chien-Chang Wu, Yousuf \& Yip, 2011). In Malaysia, MMI reported that close to 500,000 nationals suffer from depression according to the National Health and Morbidity Survey 2019 (Blue, 2020). Evidently, there is a problem that requires the attention of lawmakers to tackle mental health issues which affects the smooth running of society. Hence, law plays a pivotal role in protecting the sanctity of life. As provided above, the sanctity of life must be protected all whilst studying causes of suicide mostly induced by mental difficulties. However, the existing legal framework is inadequate in governing attempted suicide associated with mental health disorder in Malaysia. The main issue is incompatibility and the inefficiency of Section 309 of the Malaysian Penal Code in addressing attempted suicide rooted with mental difficulties, which will be delved deeper below.

The attitude of the judiciary in Malaysia regarding Section 309 of the Penal Code of the offence of attempted suicide can be observed by referring to reported and also unreported cases as some of the cases that involved Section 309 of the Penal Code are not reported mainly when it only involved that section alone. Based on reported and unreported cases regarding Section 309 of the Penal Code in Malaysia, firstly, it is obvious that the depth of the discussion is not well discussed compared to India where the court in India has analyzed Section 309 of the Penal Code in the context of the right to life and right to die. Next, it is also obvious that the cases involved did not manage to elaborate further on the ingredients needed in Section 309 of the Penal Code. This can be seen in the case of Jacob Tiang Lee Yee v Public Prosecutor [2016] 12 MLJ 72 where this case involves several charges particularly on Section 302, Section 307 and Section 309 of the Penal Code. When a discussion on the ingredients needed for each offence in the case was discussed, it only incorporates the ingredients of Section 302 and Section 307 of the Penal Code which are the offence of murder and attempted murder. After all of these elements were laid down, the discussion reverted to another issue therefore, leaving out on the elements of Section 309 of the Penal Code on the offence of attempted suicide. Thirdly, what can be observed from the same case is that the court failed to give justification on its decision in ruling that the prosecution was unable to make a prima facie case on Section 309 of the Penal Code. The prosecution is also unable to give any reasoning on their decision of not appealing on that Section. The fact of this case is that it involved a family who was involved in a serious debt. The father decided to bring the family to the "other world" by killing all of them. After killing all his family, except his 18 years old son who managed to escape when he is trying to kill him, he then attempted suicide by hanging himself by the neck by using a belt which was tied above the staircase. 
Another similarity with another case which also involved Section 302 and Section 309 of the Penal Code can be seen in the case of PP v Mudsar Rusli [2014] MLRHU 1331, where the accused was charged with Section 302 and Section 309 of the Penal Code. The accused killed his wife at his house when the couple was involved in an argument. This is due to the non-stop crying of their two years old son. At that time, the accused had not been well for almost 10 days and at the same time, the deceased was blaming the accused for not helping her with the chores. Right after, he attempted suicide by stabbing himself. The accused pleaded guilty to the charge under Section 309 of the Penal Code, thus the court sentenced him to 1-year imprisonment. Based on these two reported cases that have been analyzed, both cases have one thing in common where all of the accused only tried to commit the attempt of suicide after committing a murder. Other than that, all of the accused are not facing any mental health issues, as there was no clinical evidence to show such a state. Rather, all of them were in the state of immense pressure trying to avoid liability or losing their sense of self-control after committing a heinous crime of murder.

A reported case shows on the surface that it looks like it involved mental health issues however after further examination clinically shows that such state was absent during the commission of the crime. The case is Public Prosecutor v Foo Chee Ping [2013] MLRHU 1410, another case involving both Section 302 and Section 309 of the Penal Code. After the accused stabbed the deceased, he ran away. He claimed that his act of stabbing the deceased was because there was a voice telling him to kill him or else, the deceased will continue to suffer by being abused. Then he ran to the stadium following the voice, stabbed himself with a broken glass he picked and cut his throat and went home, everything in accord with the voice. Defendant Witness, Dr Rajinder Singh who is a consultant psychiatrist testified that the accused had damaged his brain cells by consuming ecstasy which was a type of amphetamine causing his mind to be characterised by psychotic symptoms and abnormal behaviour. Even so, the accused still had control of his cognitive thinking when he committed the offence as he was conscious of his acts.

This is because he knew his act was against the law and wrong. While approaching the charge under Section 309 of the Penal Code, the judge has defined suicide by referring to The Concise Oxford Dictionary which defines it as the intentional killing of oneself. The accused admits that the glass he used to kill himself was not capable of taking his life away as it was too small. Therefore, based on his statement where he admits stabbing himself, the court held that it is of no doubt that he inflicted the injuries on himself voluntarily, thus tantamount to an attempt to commit suicide. The fourth point that can be made by this observation is the lack of numbers for reported cases reflected that suicide is still viewed as a taboo. Furthermore, on the fifth point, since all reported cases involving Section 309 of the Penal Code are attached with a graver offence such as Section 302 and Section 307 of the Penal Code, the court has a tendency to miss on Section 309 of the Penal Code in giving sufficient discussion and elaboration on the offence. This shows that there are lacunae in the Malaysian judiciary on Section 309 of the Penal Code as there is no in-depth discussion on the offence despite having the law since the Penal Code was in force as it was adopted in pari materia with the Indian Penal Code. Other than reported cases, a reference can also be made to unreported cases involving Section 309 of the Penal Code to understand the attitude of the judiciary better.

Sixth, all unreported cases are mostly when the charge of Section 309 of the Penal Code stands alone. This shows that it was not viewed as a vital issue in Malaysia and is taken for granted. Examples of unreported cases are, on April 2017, a 24-year-old Chinese woman was fined amounting to RM 2,000 by a Magistrate after she was charged with the offence of attempted suicide for slashing her wrist several times. The Magistrate who gave her the punishment shows lack of consideration while making a remark saying "No matter how much pressure you are facing, suicide is not a solution, now you're out of the hospital, you must be charged in court anyway. You must know that attempting suicide is a crime." (New Straits Time, 2017). This shows the attitude of the court, in its lack of consideration in exercising any discretionary power. Furthermore, this attitude where the court in its shortness of compassion can be further seen where a disabled man who is depressed was also sentenced in Magistrate Court under Section 309 of the Penal Code. He attempted suicide by trying to hang himself with nylon rope from a ceiling and worst, he was not represented by any lawyers (Malaysiakini, 2020). In another case, a man was fined RM 3,000 and 3-month jail if he failed to pay the fine. The 
prosecution argued that his attempt of jumping from a balcony of a flat had inconvenienced many parties (The Star, 2020). However, in August 2020, there is a shift of attitude from the judiciary where a judge has exercised his discretionary power on an attempted suicide case where judgement from a RM 3,000 fine was reversed to a good behaviour bond.

Justice Commissioner Aslam Zainuddin at the Kuala Lumpur High Court had reversed the decision made by the Magistrate after the accused told the court that was depressed where he did not eat for 3 days, and he was living alone separated from his family while doing work at a madrasah (Hamdan, 2020). The shift of the court's attitude in this case shows that suicide has indirectly been recognised as a valid and worrying problem which needs to be tackled with some compassion instead of a punishment. Based on the cases, particularly on unreported cases, although not on all parts, there seems to be a consensus where the offenders of Section 309 of the Penal Code are mostly facing mental health issues. The next section discussed the law of Right to Die in Malaysia.

\section{Conclusion}

In conclusion, the law on Penal Code in particular had been addressed on the absence of guideline on part of the prosecution as well as the defence counsel in the light of ensuring the quality of the legal development. This issue can be seen as one of the gaps in the judicial setting that reflects the weaknesses of the law in governing the attempted suicide, thus, leading nowhere towards a better enforcement as well as to achieve the greater purpose of the law itself and for the society as well. In this setting, the World Health Organization (WHO) published a Resource Book on mental health, human rights and legislation, including a checklist of 175 specific items to be addressed in mental health legislation or policy in individual countries. The WHO resource book remains as the most comprehensive checklist for mental health legislation available, furnishing the most systematic, detailed framework for human rights analysis of mental health legislation. Thus, it is imperative to determine the extent to which the Mental Health Act 2001 will bring the Malaysian legislation in line with the guidelines provided by WHO.

\section{References}

Adinkrah, M. (2016). Anti-Suicide Laws in Nine African Countries: Criminalization, Prosecution and Penalization. African Journal of Criminology and Justice Studies, 9(1).

Ball, J. (1956). The Deterrence Concept in Criminology and Law. The Journal of Criminal Law, Criminology, And Police Science, 46(3), 347.

Behere, P., Sathyanarayana Rao, T., \& Mulmule, A. (2015). Decriminalization of attempted suicide law: Journey of Fifteen Decades. Indian Journal of Psychiatry, 57(2), 122.

Blue, C. (2021). How To Fix Malaysia's Hidden Mental Health Epidemic - CodeBlue. Retrieved 20 September 2021, from https://codeblue.galencentre.org/2020/09/02/how-to-fix-malaysiashidden-mental-health-epidemic

Chen, Y., Chien-Chang Wu, K., Yousuf, S., \& Yip, P. (2011). Suicide in Asia: Opportunities and Challenges. Epidemiologic Reviews, 34(1), 129-144.

Chia, B., Chia, A., Yee, N., \& Choo, T. (2010). Suicide Trends in Singapore: 1955-2004. Archives Of Suicide Research, 14(3), 276-283.

Department of Social Sciences of Humanities Texas A\&M University. (n.d.). Review Article Open Access Criminology Theoretical Investigation on Suicidal Acts. "Review Article Open Access Criminology Theoretical Investigation on Suicidal Acts". https://www.omicsonline.org/openaccess/criminology-theoretical-investigation-on-suicidal-acts-1522-48211000352.php?aid=86118>

Malaysiakini. (2020). Disabled man jailed for attempting to kill self amid bid to decriminalise suicide. Retrieved 15 December 2020, from https://www.malaysiakini.com/news/509364. $\begin{array}{ccccc}\begin{array}{c}\text { Fawcett, } \\ \text { https://www.ncbi.nlm.nih.gov/articles/NBK107213 }\end{array} & \text { September } & \text { 2021, } & \text { from }\end{array}$ 
Fenton, J. (2018). Attempting suicide is not a crime under Maryland law. But an Eastern Shore man was convicted of it. Retrieved 21 October 2020, from https://www.baltimoresun.com/news/crime/bs-md-suicide-criminal-charge-20180222-story.html

Goswami, G.K. (2018). Decriminalizing Attempted Suicide in India: A Paradigm Shift in Approach. The Law Faculty University of Delhi.

Hamdan, N., 2021. High Court revises RM3,000 fine to good behaviour bond for man who attempted suicide. [online] The Star. Available at: <https://www.thestar.com.my/news/nation/2020/08/11/high-court-revises-rm3000-fine-to-goodbehaviour-bond-for-man-who-attempted-suicide> [Accessed 20 September 2021].

Harris, E., \& Barraclough, B. (2021). Suicide as an outcome for mental disorders.

Harun, H.N. (2020). Amendment to decriminalise attempted suicide likely to be tabled mid-year. New Straits Times.

Ibrahim, N.H et al, (2019). The role of social support and spiritual wellbeing in predicting suicidal ideation among marginalized adolescents in Malaysia. BMC Public Health, 19(4), 553.

Jacob Tiang Lee Yee v Public Prosecutor [2016] 12 MLJ 72

Jacobs, D., \& Brewer, M. (2004). APA Practice Guideline Provides Recommendations for Assessing and Treating Patients with Suicidal Behaviors. Psychiatric Annals, 34(5), 373-380.

Lakshmi Vijayakumar et al, (2008). Socio-economic, Cultural and Religious Factors Affecting Suicide Prevention in Asia.

Mae, Y. (2021). 16,000 Malaysians are demanding the decriminalization of suicide. Retrieved 22 October 2020, from https://sea.mashable.com/culture/11853/11000-malaysians-are-demandingthe-decriminalization-of-suicide

Mental health bill decriminalising suicide passed by Parliament. (2021). Retrieved 21 October 2020, from https://indianexpress.com/article/india/mental-health-bill-decriminalising-suicide-passedby-parliament/

Mike, J. (2020). Treatment Not Prosecution: The (De) Criminalization of Attempted Suicide in Nigeria In Relation To Mental Health Issues. American University of Nigeria.

Moore, S, (2000). Decriminalisation of Suicide, Ph D. Thesis. Department of Law London School of Economics and Political Science at pp 5-11.

Most suicide cases are not tried | Daily Express Online - Sabah's Leading News Portal. (2021). Retrieved 21 October 2020, from http://www.dailyexpress.com.my/news.cfm?NewsID=112883

Ng, Y., \& Panirselvam, R. (2019). The Endgame of Section 309? An Appeal for Decriminalisation of Suicide. Malaysian Journal of Psychiatry Ejournal, 28.

Nge, L, Bakri, F, A. (2021). Suicidal Prevention using Jurisprudence. International Journal of Business, Economics and Law.

Nortajuddin, A. (2020) Suicide Spikes Amid Pandemic? <https://theaseanpost.com/article/suicidespikes-amid-pandemic>

Osafo, J., Akotia, C., N.B Quarshie, E., Boakye, K., \& Andoh-Arthur, J. (2017). Police Views of Suicidal Persons and the Law Criminalizing Attempted Suicide in Ghana: A Qualitative Study with Policy Implications. SAGE Journals.

Pal, S. (2017). Suicide: Its Moral and Legal Analysis. MS Academic.

Public Prosecutor v Foo Chee Ping [2013] MLRHU 1410

Public Prosecutor v Mudsar Rusli [2014] MLRHU 1331

Shah, A. (2018, August 26). Attempting suicide is a cry for help. News Straits Time.

Sinniah, A., Maniam, T., Oei, T., \& Subramaniam, P. (2014). Suicide Attempts in Malaysia from the Year 1969 to 2011. The Scientific World Journal, 1-13.

The Star. (2020, December 15). Court fines man RM 3k for suicide attempt. The Star. (2020). Retrieved 15 December 2020, fromhttps://www.thestar.com.my/news/nation/2020/08/04/courtfines-man-rm3k-for-suicide-attempt.

Tompo bin Yara v Public Prosecutor [2017] MLJU 127

Vijayakumar, L. (2010). Indian research on suicide. Indian Journal of Psychiatry, 52(7), 291.

Wen, L. (2021). Anti-suicide law no longer relevant, says Liow. Retrieved 20 October 2020, from https://www.thestar.com.my/news/nation/2012/07/09/antisuicide-law-no-longer-relevant-saysliow 